\title{
Association between Morphodynamic Variables by Transesophageal Echocardiography and $\mathrm{CHA}_{2} \mathrm{DS}_{2}$-Vasc Values
}

Renata Rejane Linhares, ${ }^{1 \oplus}$ Dalmo Antonio Ribeiro Moreira, ${ }^{2}$ Luciana Braz Peixoto, ${ }^{\circledR}$ Andresa Paes da $\mathrm{Cruz}^{1}{ }^{1}$ Luara Piovam Garcia, ${ }^{1 \oplus}$ Rodrigo Bellio de Mattos Barretto, ${ }^{1,2}$ David Costa de Souza Le Bihan, ${ }^{1,2}$ Carlos Eduardo Suaide Silva ${ }^{1}{ }^{\circ}$

DASA - Diagnósticos da América S/A,' São Paulo, SP - Brazil

Instituto Dante Pazzanese de Cardiologia, ${ }^{2}$ São Paulo, SP - Brazil

\section{Abstract}

Background: In atrial fibrillation (AF), the $\mathrm{CHA}_{2} \mathrm{DS}_{2}-\mathrm{VASc}$ score calculates the risk for stroke. Di Biase classified the left atrial appendage (LAA), using magnetic resonance imaging, into 4 morphological types and correlated it with cerebrovascular events. Transesophageal echocardiography (TEE) also evaluates LAA and is a more widespread technique.

Objective: To evaluate, using TEE, the possibility of characterizing LAA and to analyze its morphological aspects using the $\mathrm{CHA}_{2} \mathrm{DS}_{2}$ VASc score.

Method: A total of 247 patients were divided into three groups considering the $\mathrm{CHA}_{2} \mathrm{DS}_{2}$-VASc score: Group 1: 0 and 1; Group 2: 2 and 3 and, Group 3: $\geq 4$ points. TEE produced the echocardiographic data. LAA was classified into thrombogenic and non-thrombogenic morphologies. In the analysis of statistical tests, a significance level of $5 \%$ was adopted.

Results: The average age was 50 and $16.2 \%$ presented AF. In Group 1, we observed normal variables with a lower prevalence of $\mathrm{AF}(8.7 \%, \mathrm{p}<0.001)$. In group 2, spontaneous contrast was detected in $26.7 \%$, $(\mathrm{p}<0.001)$, thrombus in $6.7 \%(\mathrm{p}=0.079)$ and flow velocity in LAA $<0.4 \mathrm{~m} / \mathrm{s}$ in $22.7 \%(\mathrm{p}<0.001)$ of the cases. Group 3 presented the highest percentages of $\mathrm{AF}(31.8 \%, \mathrm{p}<0.001)$, stroke/ TIA $(77.3 \%, \mathrm{p}<0.001), \mathrm{EF}<55 \%(18.2 \%, \mathrm{p}=0.010)$ and higher prevalence of thrombogenic type LAA $(72.7 \%, \mathrm{p}=0.014)$. A higher occurrence of stroke/TIA was observed in patients with thrombogenic LAA $(25.2 \%)$ compared to the non-thrombogenic group $(11.2 \%),(p=0.005)$.

Conclusions: The thrombogenic morphology of LAA identified in TEE presented a higher risk of stroke regardless of the $\mathrm{CHA}_{2} \mathrm{DS}_{2} \mathrm{VASc}$ score. Patients with higher scores had greater abnormalities in echocardiographic variables. (Int J Cardiovasc Sci. 2019;32(5):460-470)

Keywords: Stroke; Atrial Fibrillation, Atrial Appendage, Arrhythmias, Cardiac; Myocardial Contraction; Echocardiography, Transesophageal.

\section{Introduction}

Stroke is the leading cause of death in Brazil and the heart is an important embolic source responsible for this complication. Atrial fibrillation accounts for $20 \%$ of stroke cases. The treatment of this arrhythmia is an important challenge for the medical community. In addition to reestablishing sinus rhythm or not, or only performing ventricular rate control, anticoagulant therapy is definitely the one that improves the prognosis of affected patients. ${ }^{1,2}$ The recommendation of anticoagulation is objectively performed by characterizing the individual risk of systemic thromboembolism based on the $\mathrm{CHA}_{2} \mathrm{DS}_{2}$ VASc score ( $\mathrm{C}=$ heart failure; $\mathrm{H}=$ hypertension; $\mathrm{A}=$ age $>75$ years; $\mathrm{D}=$ diabetes mellitus; $\mathrm{S}=$ history of stroke; $\mathrm{V}=$ peripheral vascular disease; $\mathrm{A}=$ age above 64 years; $S=$ female sex). Age $>75$ years and history of stroke generate two points in the score while the other variables generate only one point. Higher risk for 
systemic thromboembolism occurs in patients whose score is $\geq 2$ for males or $\geq 3$ for females. ${ }^{2}$

Left atrial appendage (LAA) represents one of the main sources of cardiac thrombi responsible for stroke in patients with $\mathrm{AF}^{3-6}$ and this is probably due to the anatomical characteristics of this structure, which facilitate slower blood flow inside it. An interesting finding is that LAA thrombosis can occur even in patients with a lowered $\mathrm{CHA}_{2} \mathrm{DS}_{2} \mathrm{VASc}$ score $(<2)$ and this may be related to its morphology. Di Biase et al., ${ }^{3}$ through magnetic resonance imaging and computed tomography, classified LAA into 4 different morphologies: chicken wing, windsock, cactus and cauliflower, according to their appearance in the imaging scans. With this characterization, these authors were able to correlate each morphological type with the risk of stroke, being greater in those whose morphology was different from the chicken wing morphology. ${ }^{3}$ The more complex morphology of these non-chicken wing structures may explain the increased risk of atrial thrombosis.

Two-dimensional transesophageal echocardiography (2D TEE) has been widely used to assess the left atrium and to characterize the structure and function of LAA. It is the method of choice to evaluate the presence of thrombus, as it provides a better imaging of these structures compared to transthoracic echocardiography, has greater accessibility and lower cost than magnetic resonance imaging and computed tomography, and can thus help identify risk factors for stroke. Agreement between the TEE findings and the $\mathrm{CHA}_{2} \mathrm{DS}_{2}$-VASc score is still poorly explored in our country.

The objectives of this study were to evaluate, using TEE, the echocardiographic data with the $\mathrm{CHA}_{2} \mathrm{DS}_{2}$ VASc score. Besides, to establish its usefulness in the characterization of the LAA morphology for thromboembolic risk stratification, based on the studies with magnetic resonance imaging.

\section{Material and methods}

A randomized retrospective study that evaluated data from patients undergoing outpatient transesophageal echocardiography between August 2012 and June 2015 in a specialized laboratory. All patients signed an informed consent form. The echocardiographic study was performed by 2 experienced and qualified echocardiographers in state-of-the-art equipment with second harmonics (GEVingmed Ultrasound, Vivid 7 and S6, Horten, Norway and ESAOTE My Lab 70, Florence, Italy).
The clinical indications of patients referred for the scan were: of the 207 patients with no history of atrial fibrillation, $50.2 \%$ interatrial septum evaluation, $25.2 \%$ thrombus investigation, $8.7 \%$ non-specific cardiac evaluation, 4, 4\% thoracic aorta evaluation, 3.8\% suspected endocarditis, $3.8 \%$ interventricular septum evaluation, $2 \%$ valvular heart disease evaluation, $1 \%$ cardiac tumor investigation, $0.5 \%$ syncope, $0.5 \%$ myocardiopathy. In patients with a history of atrial fibrillation, the indications were: $82.5 \%$ thrombus investigation, $10 \%$ interatrial septum evaluation and $7.5 \%$ aortic evaluation. Of all patients, $18.6 \%$ had a history of stroke/TIA and $5.7 \%$ had coronary artery disease.

Using a questionnaire, considering the clinical data, the $\mathrm{CHA}_{2} \mathrm{DS}_{2}-\mathrm{VASc}$ score of each patient was quantified according to the European guidelines. ${ }^{2}$ Two points were assigned to the risks considered larger represented by previous history of stroke, TIA or systemic embolism and age greater than 75 years, and one point for other risk factors. Patients with a history of stroke or transient ischemic attack, and individuals with sinus rhythm and history of atrial fibrillation were also identified.

Two-dimensional transthoracic echocardiography with previous color Doppler was performed to determine ejection fraction and the degree of left atrial dilatation. Then, TEE was employed to look for thrombus and spontaneous contrast, and to determine blood flow velocity in LAA and its morphology. At the TEE scan, local anesthetic was initially administered via the oropharyngeal aspiration route with lidocaine spray and then light sedation with midazolam, dolanthine and propofol as required. Patients were monitored throughout the procedure with evaluation of vital signs, heart rate and pulse oximetry saturation. The room was equipped with oxygen therapy support, cardio-defibrillator, and equipment and medications needed for any emergencies. After transesophageal catheterization, echocardiographic images were taken at the mid-esophagus level of the whole heart, mainly at the left atrial appendage and at the proximal sections at $0^{\circ}, 60^{\circ}, 90^{\circ}$ and $120^{\circ}$ and later at the transgastric section at $0^{\circ}$ and $90^{\circ}$. We excluded patients with contraindication for outpatient ECOTE, patients undergoing left atrial appendage occlusion, patients with primary valvopathy with hemodynamic repercussion or undergoing valve surgery.

The patients were separated into 3 different groups according to the $\mathrm{CHA}_{2} \mathrm{DS}_{2}-\mathrm{VASc}$ score: group 1: 0 and 1 point, group 2: 2 and 3 points and group 3: $\geq 4$ points. The variables evaluated were: ejection fraction (Teichholz 
or Simpson methods), degree of left atrial dilation, presence of spontaneous contrast, imaging suggestive of thrombus, and determination of LAA blood flow velocity by pulsatile Doppler.

In the echocardiographic characterization of left atrial appendage, the morphologies were separated into two different types: a) non-thrombogenic determined by its regular and smooth internal surface associated with a prominent angulation, called "chicken wing" according to Di Biase et al. (this image could be well delineated by TEE) (Figure 1); b) thrombogenic type represented by LAA with irregularities and lobules on its internal surface (corresponding to non-"chicken wing" morphologies) (Figure 2). The specific morphology of the "windsock," "cactus" and "cauliflower" types was not considered due to difficulties in taking images that could characterize these forms of presentation (Figure 3).

This paper was registered with the CEP (Ethics and Research Committee) of Instituto Dante Pazzanese de Cardiologia with the following CAAE registration number: 38696114.7.0000.5462, approved on 17/11/2014, opinion number: 875.528 .

\section{Statistical analysis}

For statistical analysis, the statistical software SPSS 20.0 was used. For all statistical tests, a significance level of $5 \%$ was adopted.
Initially, the data were descriptively analyzed: for the categorical variables, absolute and relative frequencies were presented. For the numerical variables, summarymeasures were presented (mean, minimum, maximum, quartiles and standard deviation).

To check the association between categorical variables, the Chi-Square test was used, or alternatively in cases of small samples, Fisher's exact test. A comparison of the means between two groups was performed using Student's t-test for independent samples. The comparison of means for more than two groups was performed by Variance Analysis. If mean differences were detected, these were found using Duncan's multiple comparisons with a global significance level of $5 \%$. The KolmogorovSmirnov test was used to check normality in data distribution. In case of data normality violation, the means were compared using the non-parametric KruskalWallis test. Once the differences of means were detected by this test, the localization of the differences was performed through Dunn-Bonferroni tests, maintaining a global significance level of 5\%.

\section{Results}

We evaluated 247 patients, predominantly females $(56.3 \%)$. The mean age was $50 \pm 16.6$ years. Most patients were in sinus rhythm and only $16.2 \%$ had atrial fibrillation (Chart 1).

A $\quad$ B

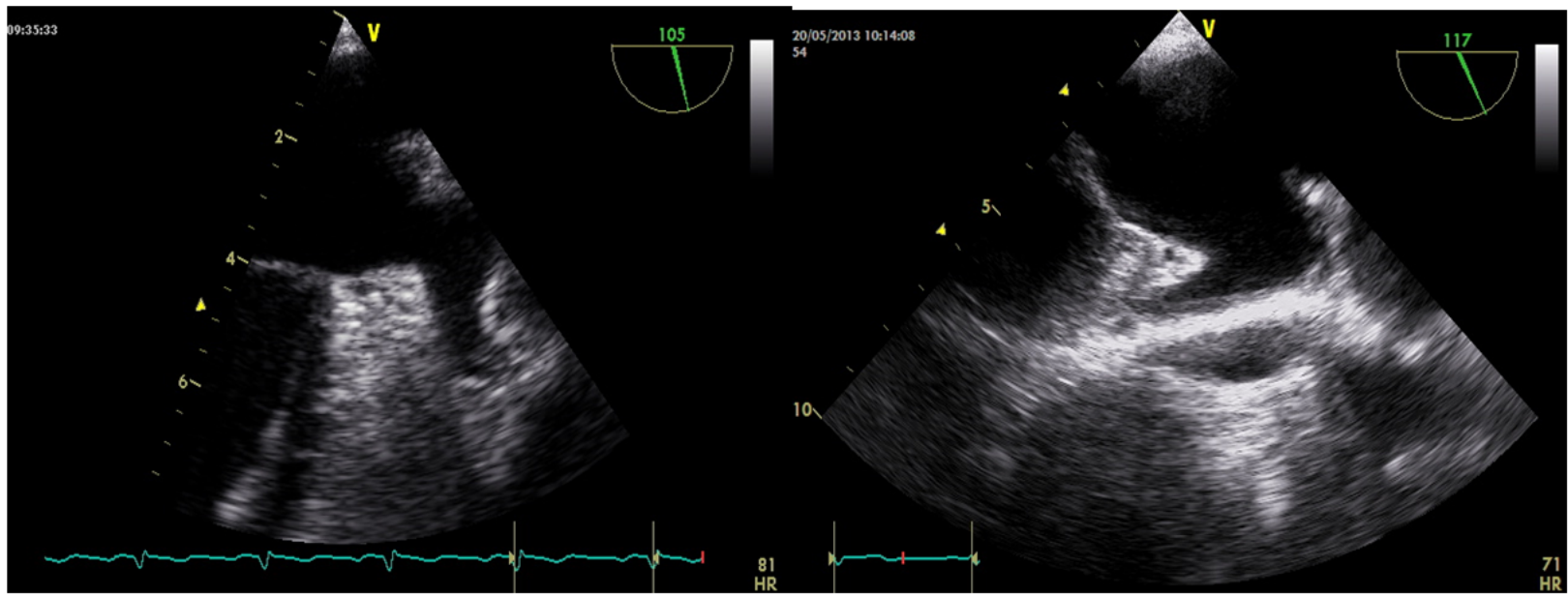

Figure 1 - A and B: Example of non-thrombogenic left atrial appendage (similar to chicken wing by nuclear magnetic resonance imaging), a prominent angulation of the structure with its smooth inner surface is found. 
C

D

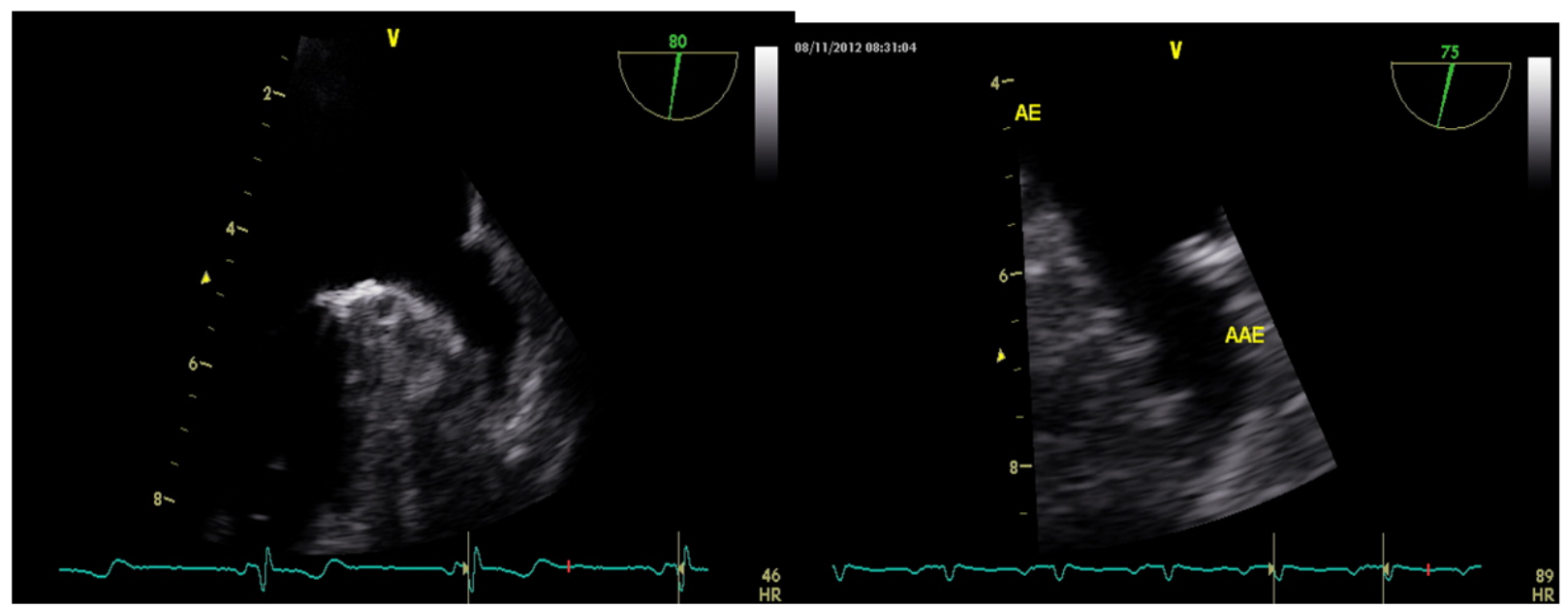

Figure 2 - C and D: Example of thrombogenic left atrial appendage (similar to windsock, cactus and cauliflower by nuclear magnetic resonance imaging), there is no prominent angulation of the structure with its irregular internal surface.

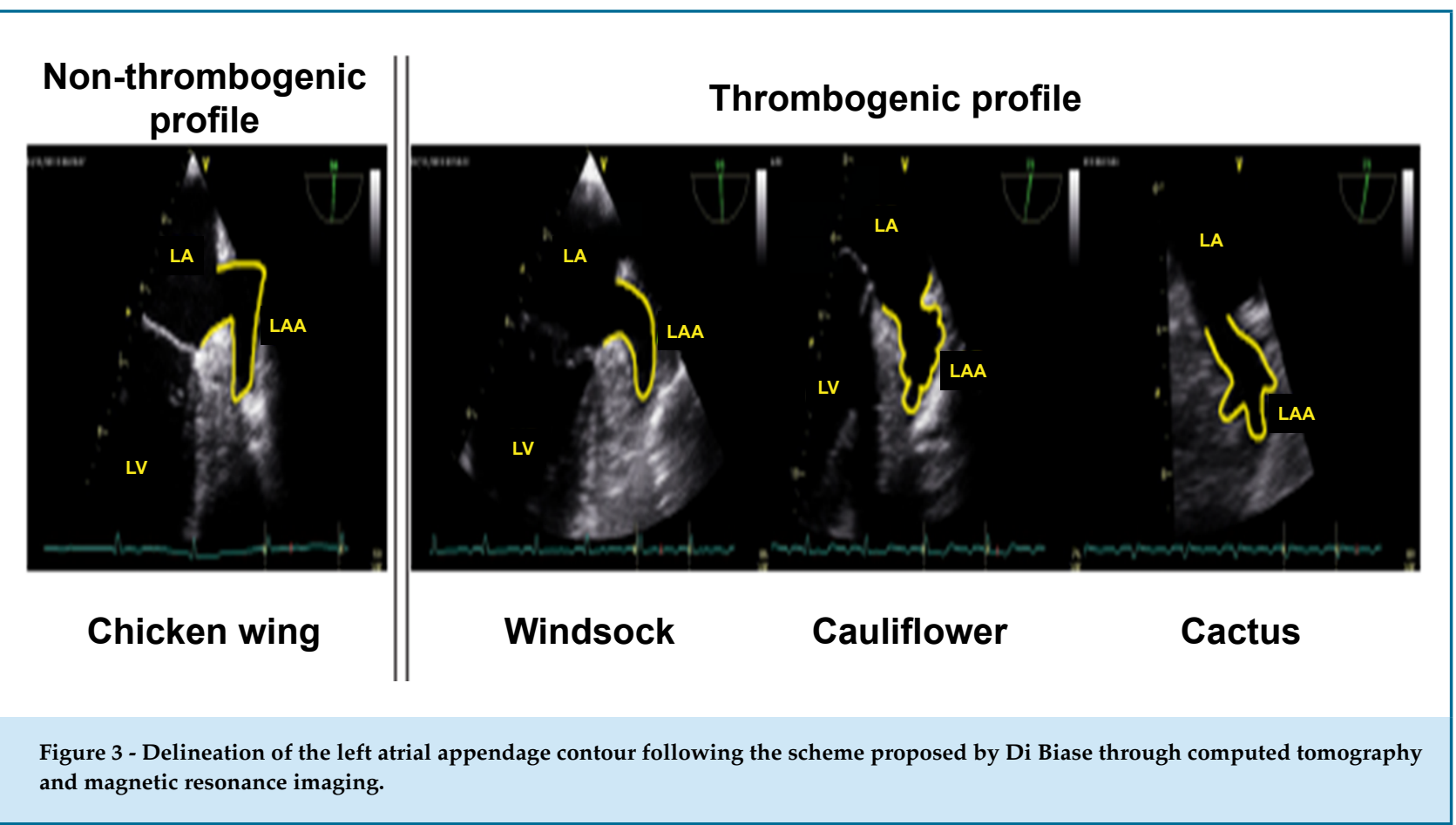

Group 1 patients $\left(\mathrm{CHA}_{2} \mathrm{DS}_{2}-\mathrm{VASc}\right.$ - entre 0 e 1) presented the lowest percentages of $\mathrm{AF}(8.7 \%)$, spontaneous contrast $(8.7 \%)$, left atrium dilation $(14.0 \%)$ and of heart failure $(2.0 \%)$ compared to other groups. In addition, this group had the highest percentages of ejection fraction higher than $55 \%(96.0 \%)$, and LAA mean flow velocity higher than $0.4 \mathrm{~m} / \mathrm{s}(95.3 \%)$ (table 1$)$.

Patients in group $2\left(\mathrm{CHA}_{2} \mathrm{DS}_{2}-\mathrm{VASc}\right.$ - between 2 and 3) had the highest percentages of spontaneous contrast $(26.7 \%)$, mild left atrial dilation $(22.7 \%)$, presence of 


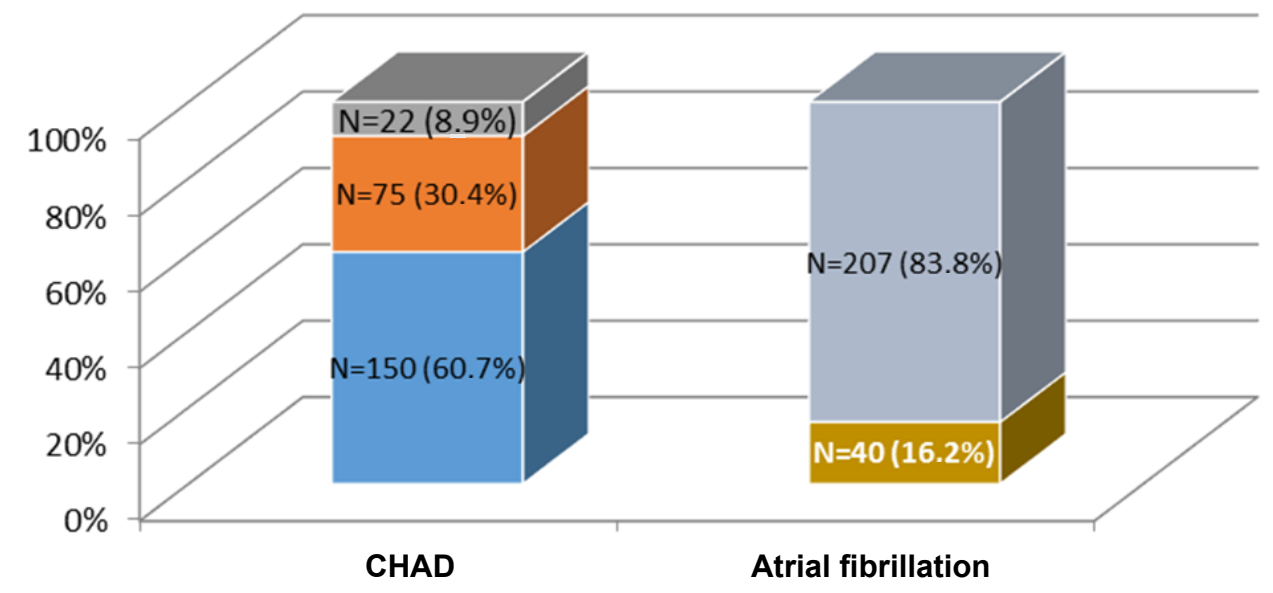

CHAD-0 to 1 CHAD-2 to $3=$ CHAD-4 and

Presence of AF $\square$ Absence of AF more

Chart 1 - Distribution of patients by $\mathrm{CHA}_{2} \mathrm{DS}_{2}$-VASc values and atrial fibrillation.

thrombus $(6.7 \%)$ and LAA mean velocity $<0.4 \mathrm{~m} / \mathrm{s}$ $(22.7 \%)$ compared to other groups. Besides this, it presented the second highest percentage of AF (26.7\%), moderate left atrial dilation degree $(16.0 \%)$, stroke/ TIA $(38.7 \%)$, ICO $(10.7 \%)$, and ejection fraction smaller than $55 \%(13.3 \%)$, compared to other groups (Table 1).

Finally, patients in group $3\left(\mathrm{CHA}_{2} \mathrm{DS}_{2}-\mathrm{VASc} \geq 4\right)$ presented the highest AF percentages $(31.8 \%)$, moderate left atrial dilation $(22.7 \%)$, stroke/TIA $(77.3 \%)$, ICO $(13.6 \%)$, with an ejection fraction of smaller than $55 \%$ (18.2\%). The LAA morphology of the thrombogenic type was present in $72.7 \%$ of these patients (Table 1).

Table 1 shows an association between the $\mathrm{CHA}_{2} \mathrm{DS}_{2}-$ VASc values and hemodynamic and structural variables, except for the presence of thrombus $(p=0.079)$.

Table 2 shows the association of AF with spontaneous contrast $(p<0.001)$, left atrial dilation degree $(p<0.001)$, presence of thrombus ( $p=0.001)$, decreased ejection fraction $(p=0.007)$ and low LAA flow velocity $(p<0.001)$. There were no associations of the other variables with $\mathrm{AF}$. In the group of patients with $\mathrm{AF}$, there was a higher occurrence of spontaneous contrast $(67.5 \%$ vs. $3.4 \%$ in the group without AF), mild, moderate and severe degrees of left atrial dilation $(35.0 \%, 32.5 \%$ and $10.0 \%$ versus $9.7 \%, 3.4 \%$ and $0.5 \%$, respectively, in the non-AF group), presence of thrombus $(17.5 \%)$, ejection fraction smaller than $55 \%$ (20.0\% versus $5.8 \%$ in the group without AF) and mean LAA velocity smaller than $0.4 \mathrm{~m} / \mathrm{s}(60.0 \%$ vs. $1.4 \%$ in the group without atrial fibrillation).

The association of LAA morphology with a history of stroke/TIA is shown in table 3. There is a higher occurrence of stroke/TIA in patients with thrombogenic LAA $(25.2 \%)$ compared to the non-thrombogenic group $(11.2 \%),(\mathrm{p}=0.005)$, regardless of the $\mathrm{CHA}_{2} \mathrm{DS}_{2}-\mathrm{Vasc}$ score (Table 3).

\section{Discussion}

Atrial fibrillation is the most common type of supraventricular tachyarrhythmia in the adult population. Its prevalence ranges from 1.5 to $2 \%$ in the age group of 60 to 70 years, increasing to more than $15 \%$ in the population aged over $80 .{ }^{1}$ This arrhythmia is associated with a 5-fold increase in stroke risk and a 3-fold increase in the incidence of congestive heart disease in addition to evolving with high mortality. ${ }^{2}$

The main international guidelines guide the implementation of a risk stratification for cerebrovascular events in patients with AF, in order to identify patients with greater and lower risk for this complication. From this point on, the preventive drug treatment begins, and the best therapeutic choice can be established, such as 
Table 1 - Distribution of patients by hemodynamic and structural variables, according to $\mathrm{CHA}_{2} \mathrm{DS}_{2}$-VASc values

\begin{tabular}{|c|c|c|c|c|c|c|c|c|}
\hline & \multicolumn{6}{|c|}{$\mathrm{CHA}_{2} \mathrm{DS}_{2} \mathrm{VASc}$} & \multirow{2}{*}{\multicolumn{2}{|c|}{ Total }} \\
\hline & \multicolumn{2}{|c|}{0 to 1} & \multicolumn{2}{|c|}{2 to 3} & \multicolumn{2}{|c|}{$\geq 4$} & & \\
\hline & $\mathbf{N}$ & $\%$ & $\mathbf{N}$ & $\%$ & $\mathbf{N}$ & $\%$ & $\mathbf{N}$ & $\%$ \\
\hline Atrial fibrillation & 150 & & 75 & & 22 & & 247 & $100.0 \%$ \\
\hline Yes & 13 & $8.7 \%$ & 20 & $26.7 \%$ & 7 & $31.8 \%$ & 40 & $16.2 \%$ \\
\hline No & 137 & $91.3 \%$ & 55 & $73.3 \%$ & 15 & $68.2 \%$ & 207 & $83.8 \%$ \\
\hline \multicolumn{9}{|c|}{$\mathrm{x}^{2}(2, \mathrm{~N}=247)=16.28-\mathrm{p}<0.001$} \\
\hline Spontaneous contrast & 150 & & 75 & & 22 & & 247 & $100.0 \%$ \\
\hline Yes & 10 & $6.7 \%$ & 20 & $26.7 \%$ & 4 & $18.2 \%$ & 34 & $13.8 \%$ \\
\hline No & 140 & $93.3 \%$ & 55 & $73.3 \%$ & 18 & $81.8 \%$ & 213 & $86.2 \%$ \\
\hline \multicolumn{9}{|c|}{$x^{2}(2, N=247)=17.25-p<0.001$} \\
\hline Left atrial dilation degree & 150 & & 75 & & 22 & & 247 & $100.0 \%$ \\
\hline None & 129 & $86.0 \%$ & 44 & $58.7 \%$ & 15 & $68.2 \%$ & 188 & $76.1 \%$ \\
\hline Mild & 15 & $10.0 \%$ & 17 & $22.7 \%$ & 2 & $9.1 \%$ & 34 & $13.8 \%$ \\
\hline Moderate & 3 & $2.0 \%$ & 12 & $16.0 \%$ & 5 & $22.7 \%$ & 20 & $8.1 \%$ \\
\hline Severe & 3 & $2.0 \%$ & 2 & $2.7 \%$ & 0 & $.0 \%$ & 5 & $2.0 \%$ \\
\hline \multicolumn{9}{|l|}{ Fisher's exact test $-\mathrm{p}<0.001$} \\
\hline Presence of thrombus & 150 & & 75 & & 22 & & 247 & $100.0 \%$ \\
\hline Yes & 2 & $1.3 \%$ & 5 & $6.7 \%$ & 0 & $.0 \%$ & 7 & $2.8 \%$ \\
\hline No & 148 & $98.7 \%$ & 70 & $93.3 \%$ & 22 & $100.0 \%$ & 240 & $97.2 \%$ \\
\hline \multicolumn{9}{|l|}{ Fisher's exact test $-\mathrm{p}=0.079$} \\
\hline Stroke/TIA & 150 & & 75 & & 22 & & 247 & $100.0 \%$ \\
\hline Yes & 0 & $.0 \%$ & 29 & $38.7 \%$ & 17 & $77.3 \%$ & 46 & $18.6 \%$ \\
\hline No & 150 & $100.0 \%$ & 46 & $61.3 \%$ & 5 & $22.7 \%$ & 201 & $81.4 \%$ \\
\hline \multicolumn{9}{|c|}{$x^{2}(2, N=247)=104.14-p<0.001$} \\
\hline ICO & 150 & & 75 & & 22 & & 247 & $100.0 \%$ \\
\hline Yes & 3 & $2.0 \%$ & 8 & $10.7 \%$ & 3 & $13.6 \%$ & 14 & $5.7 \%$ \\
\hline No & 147 & $98.0 \%$ & 67 & $89.3 \%$ & 19 & $86.4 \%$ & 233 & $94.3 \%$ \\
\hline \multicolumn{9}{|l|}{ Fisher's exact test $-\mathrm{p}=0.004$} \\
\hline Ejection fraction - type & 150 & & 75 & & 22 & & 247 & $100.0 \%$ \\
\hline $\mathrm{EF}<55 \%$ & 6 & $4.0 \%$ & 10 & $13.3 \%$ & 4 & $18.2 \%$ & 20 & $8.1 \%$ \\
\hline $\mathrm{EF} \geq 55 \%$ & 144 & $96.0 \%$ & 65 & $86.7 \%$ & 18 & $81.8 \%$ & 227 & $91.9 \%$ \\
\hline \multicolumn{9}{|c|}{$x^{2}(2, N=247)=9.15-p=0.010$} \\
\hline $\begin{array}{l}\text { Mean left atrial appendage } \\
\text { velocity - type }\end{array}$ & 150 & & 75 & & 22 & & 247 & $100.0 \%$ \\
\hline$<0.4 \mathrm{~m} / \mathrm{s}$ & 7 & $4.7 \%$ & 17 & $22.7 \%$ & 3 & $13.6 \%$ & 27 & $10.9 \%$ \\
\hline$\geq 0.4 \mathrm{~m} / \mathrm{s}$ & 143 & $95.3 \%$ & 58 & $77.3 \%$ & 19 & $86.4 \%$ & 220 & $89.1 \%$ \\
\hline
\end{tabular}


Cont. Table 1 - Distribution of patients by hemodynamic and structural variables, according to $\mathrm{CHA}_{2} \mathrm{DS}_{2}-\mathrm{VASc}$ values

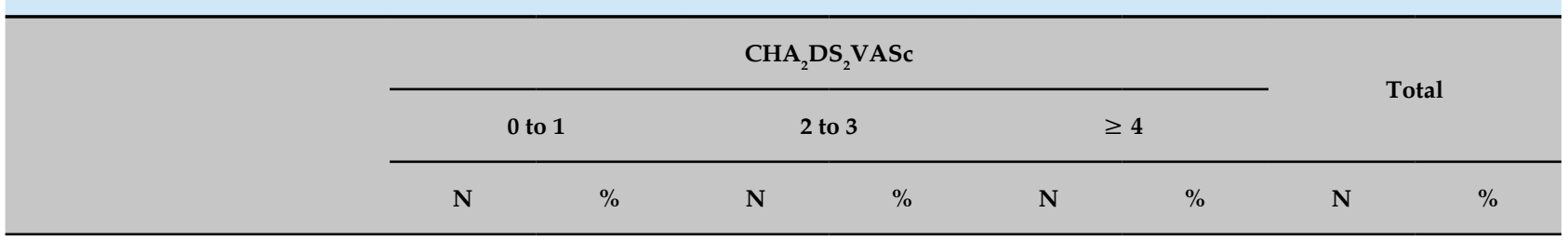

$x^{2}(2, N=247)=16.82-p<0.001$

\begin{tabular}{|c|c|c|c|c|c|c|c|c|}
\hline LAA group & 150 & & 75 & & 22 & & 247 & $100.0 \%$ \\
\hline Thrombogenic & 69 & $46.0 \%$ & 46 & $61.3 \%$ & 16 & $72.7 \%$ & 131 & $53.0 \%$ \\
\hline Non-thrombogenic & 81 & $54.0 \%$ & 29 & $38.7 \%$ & 6 & $27.3 \%$ & 116 & $47.0 \%$ \\
\hline
\end{tabular}

$\mathrm{x}^{2}(2, \mathrm{~N}=247)=8.48-\mathrm{p}=0.014$

Non-thrombogenic: chicken wing; Thrombogenic: windsock, cauliflower and cactus; TIA: transient ischemic attack; ICO: coronary insufficiency; EF: ejection fraction; LAA: left atrial appendage.

vitamin $\mathrm{K}$ antagonists (such as warfarin, with a target INR of 2.0-3.0), or with factor XA blocking anticoagulants, such as rivaroxaban or apixaban, or the direct thrombin inhibitor dabigatran. ${ }^{7}$

\section{Risk scores and stroke in patients with AF}

The risk of stroke increased with the $\mathrm{CHA}_{2} \mathrm{DS}_{2}-\mathrm{VASc}$ score, ranging from $0.84 \%$ (0 point), $1.75 \%$ (1 point), 2.69 (2 points) and $3.2 \%$ (3 points). ${ }^{2,8}$ Patients are classified as low risk $\left(\mathrm{CHA}_{2} \mathrm{DS}_{2}-\mathrm{VASc}\right.$ score $=0$ to 1$)$, moderate $\left(\mathrm{CHA}_{2} \mathrm{DS}_{2}-\mathrm{VASc}\right.$ score $=1$ to 2$)$ and high risk $\left(\mathrm{CHA}_{2} \mathrm{DS}_{2}-\right.$ VASc score $\geq 3$ ) for cerebrovascular ischemic events. In patients without risk factors, antithrombotic therapy is not recommended (Class I level of evidence A). ${ }^{8}$ On the other hand, in patients considered to be at high risk, antithrombotic therapy is recommended through oral anticoagulation. ${ }^{9}$ The benefits of antithrombotic therapy are not yet evident in patients considered to be at moderate risk. According to the latest European guideline on the management of AF (2016), oral anticoagulation is recommended for patients considered to be at moderate risk, but the risk of bleeding complications and the patients' preference should be assessed first (Class IIa level of evidence A), as also proposed by the latest guidelines of the American Heart Association/ American College of Cardiology Foundation (2011), which recommends considering the use of aspirin or oral anticoagulation (Class IIa). ${ }^{1,2}$

In clinical practice for patients presenting $\mathrm{CHA}_{2} \mathrm{DS}_{2} \mathrm{VASc}$ $\leq 2$ score, the risk of bleeding would outweigh any benefits of anticoagulation, thus reducing its net benefit, since patients at low risk for thromboembolic complications are considered. However, there are reports that these patients have some risk and that anticoagulation should be considered. Some other type of information would be needed to characterize this individual and make anticoagulation effective. A probable explanation for the risk of some low-risk patients with stroke may be based on left atrial appendage morphology.

\section{Association between TEE data and the risk of systemic thromboembolism}

TEE has a greater sensitivity in the detection of intracardiac thrombi, especially those located in the atria compared to the transthoracic scan. Besides, it provides a better left atrial appendage evaluation, as it evaluates its shape and determine important hemodynamic parameters such as blood flow velocity, which is an important predictor of thrombus formation, which is not possible using transthoracic echocardiography. TEE also has greater accessibility and lower investigative cost compared to magnetic resonance imaging and computed tomography.

The relationship between the findings of transesophageal echocardiography and the $\mathrm{CHA}_{2} \mathrm{DS}_{2}$ VASc score has not yet been established in our country, since most studies looks into the association in the presence of thrombus with the score. ${ }^{10,11}$ As patients with a higher $\mathrm{CHA}_{2} \mathrm{DS}_{2}-\mathrm{VASc}$ score have more comorbidities, they are expected to have more abnormalities in echocardiographic parameters, predisposing to thrombus formation and increased risk of stroke/TIA. ${ }^{12-14}$ 
Table 2 - Distribution of patients by hemodynamic and structural variables, according to Atrial Fibrillation

\begin{tabular}{|c|c|c|c|c|c|c|}
\hline & \multicolumn{4}{|c|}{ Atrial fibrillation } & \multirow{2}{*}{\multicolumn{2}{|c|}{ Total }} \\
\hline & \multicolumn{2}{|c|}{ Yes } & \multicolumn{2}{|c|}{ No } & & \\
\hline & $\mathbf{N}$ & $\%$ & $\mathbf{N}$ & $\%$ & $\mathbf{N}$ & $\%$ \\
\hline Spontaneous contrast & 40 & $100.0 \%$ & 207 & $100.0 \%$ & 247 & $100.0 \%$ \\
\hline Yes & 27 & $67.5 \%$ & 7 & $3.4 \%$ & 34 & $13.8 \%$ \\
\hline No & 13 & $32.5 \%$ & 200 & $96.6 \%$ & 213 & $86.2 \%$ \\
\hline
\end{tabular}

$\mathrm{x}^{2}(1, \mathrm{~N}=247)=116.10-\mathrm{p}<0.001$

Left atrial dilation degree

40

None

Mild

Moderate

Severe

Fisher's exact test $-\mathrm{p}<0.001$

Presence of thrombus

Yes

No

Fisher's exact test $-\mathrm{p}<0.001$

Stroke/TIA

Yes

No

$x^{2}(1, N=171)=0.04-p=0.842$

$\mathrm{ICO}$

Yes

No

Fisher's exact test $-\mathrm{p}=0.706$

Ejection fraction - type

$$
\begin{aligned}
& \mathrm{EF}<55 \% \\
& \mathrm{EF} \geq 55 \%
\end{aligned}
$$

Fisher's exact test $-\mathrm{p}=0.007$

Mean left atrial appendage velocity - type

$$
\begin{aligned}
& <0.4 \mathrm{~m} / \mathrm{s} \\
& \geq 0.4 \mathrm{~m} / \mathrm{s}
\end{aligned}
$$

Fisher's exact test $-\mathrm{p}<0.001$

$\begin{array}{lc}100.0 \% & 207 \\ 22.5 \% & 179 \\ 35.0 \% & 20 \\ 32.5 \% & 7 \\ 10.0 \% & 1\end{array}$

$100.0 \%$

$86.5 \%$

$100.0 \%$

$82.5 \%$

207

$100.0 \%$

$100.0 \%$

\section{LAA group}

Thrombogenic

$100.0 \%$

$40.0 \%$

204

$98.6 \%$

220

$89.1 \%$

Non-thrombogenic

$100.0 \%$

99

$47.8 \%$

116

$47.0 \%$

$\mathrm{x}^{2}(1, \mathrm{~N}=247)=0.38-\mathrm{p}=0.537$ 
Table 3 - Distribution of patients by spontaneous contrast, thrombus and stroke/TIA, according to LAA type

\begin{tabular}{|c|c|c|c|c|c|c|}
\hline & \multicolumn{6}{|c|}{ LAA groups } \\
\hline & \multicolumn{2}{|c|}{ Thrombogenic } & \multicolumn{2}{|c|}{ Non-thrombogenic } & \multicolumn{2}{|c|}{ Total } \\
\hline & $\mathbf{N}$ & $\%$ & $\mathbf{N}$ & $\%$ & $\mathbf{N}$ & $\%$ \\
\hline Spontaneous contrast & 131 & $100.0 \%$ & 116 & $100.0 \%$ & 247 & $100.0 \%$ \\
\hline Yes & 20 & $15.3 \%$ & 14 & $12.1 \%$ & 34 & $13.8 \%$ \\
\hline No & 111 & $84.7 \%$ & 102 & $87.9 \%$ & 213 & $86.2 \%$ \\
\hline \multicolumn{7}{|c|}{$x^{2}(1, N=247)=0.53-p=0.467$} \\
\hline Presence of thrombus & 131 & $100.0 \%$ & 116 & $100.0 \%$ & 247 & $100.0 \%$ \\
\hline Yes & 5 & $3.8 \%$ & 2 & $1.7 \%$ & 7 & $2.8 \%$ \\
\hline No & 126 & $96.2 \%$ & 114 & $98.3 \%$ & 240 & $97.2 \%$ \\
\hline \multicolumn{7}{|c|}{ Fisher's exact test $-\mathrm{p}=0.453$} \\
\hline Stroke/TIA & 131 & $100.0 \%$ & 116 & $100.0 \%$ & 247 & $100.0 \%$ \\
\hline Yes & 33 & $25.2 \%$ & 13 & $11.2 \%$ & 46 & $18.6 \%$ \\
\hline No & 98 & $74.8 \%$ & 103 & $88.8 \%$ & 201 & $81.4 \%$ \\
\hline$x^{2}(1, N=247)=7.94-p$ & & & & & & \\
\hline
\end{tabular}

In our study, after an analysis of 247 patients without primary valvopathy who underwent transesophageal echocardiography in an outpatient setting, 207 in sinus rhythm and 40 with history of AF, there was an association of all echocardiographic data analyzed (spontaneous contrast, left atrial dimensions, ejection fraction and blood flow velocity in LAA) with the $\mathrm{CHA}_{2} \mathrm{DS}_{2}$-Vasc score, except for the presence of atrial thrombus $(p=0.079)$. These findings confirm our initial suspicion that individuals with a high-risk score, even in sinus rhythm, already have important structural and functional cardiac changes that could be the future substrate for thrombus formation.

Willens et al. retrospectively analyzed 167 patients undergoing TEE, with a mean age of 66 years and nonvalvular AF. These authors described an increase in the prevalence of risk factors for thromboembolism the higher the $\mathrm{CHA}_{2} \mathrm{DS}_{2}$-VASc score. ${ }^{15}$ Another study, published by Parikh et al., ${ }^{16}$ presented a retrospective analysis of 455 patients with atrial flutter who underwent transesophageal echocardiography. This group found that the sensitivity for the presence of thrombus and spontaneous contrast in patients classified as high risk in the $\mathrm{CHADS}_{2}$ and
$\mathrm{CHA}_{2} \mathrm{DS}_{2}-\mathrm{VASc}$ scores was $64.8 \%$ and $88.7 \%$, respectively $(\mathrm{p}=0.0001)$, and the specificity $52.6 \%$ and $28.9 \%$, respectively $(\mathrm{p}=0.0001)$. Both the $\mathrm{CHA}_{2} \mathrm{DS}_{2}-\mathrm{VASc}$ and the $\mathrm{CHADS}_{2}$ score are useful for the stratification of stroke risk in other clinical situations, such as atrial flutter. The $\mathrm{CHA}_{2} \mathrm{DS}_{2}-\mathrm{VASc}$ protocol had greater sensitivity for the detection of atrial thrombosis and spontaneous contrast at the expense of reduced specificity. ${ }^{16}$

In our study, when we considered only those with $\mathrm{AF}$, we identified a greater presence of spontaneous contrast compared to the group that was in sinus rhythm $(67.5 \%$ $\mathrm{x} 3.4 \%, \mathrm{p}<0.001)$, higher chances of mild, moderate and severe atrial dilation $(35 \%, 32.5 \%, 10 \%$ vs $9.7 \%$, $3.4 \%$ and $0.5 \%$, respectively, $\mathrm{p}<0.001$ ). There was also a valid association with thrombus in the presence of this arrhythmia $(17.5 \%, \mathrm{p}<0.001)$.

\section{Morphology of LAA and risk of thromboembolism and stroke}

LAA is one of the main sources of cardiac thrombi responsible for cerebrovascular thrombotic events in patients with AF. ${ }^{3-6}$ Di Biase et al., ${ }^{3}$ through magnetic 
resonance imaging and computed tomography, classified 4 different types of LAA and correlated each type with risk of stroke. We evaluated 932 patients who were candidates to ablation of AF refractory to clinical treatment. Computed tomography was done to 499 patients and magnetic resonance imaging was done in 433 patients, and all were screened for history of stroke/ TIA. Each LAA morphology was categorized into one of the following four types: chicken wing, windsock, cauliflower and cactus. The results revealed that patients with the non-"chicken wing" morphology presented three times higher prevalence of stroke/TIA than those with chicken wing morphology $(12 \% \times 4 \%)$. Compared to the chicken wing morphology, those patients with cactus, windsock and cauliflower appendages were at risk increased 4, 5 and up to 8 times, respectively. ${ }^{3}$

During our routine, it was found that the chicken wing type was easily identified by transesophageal echocardiography and although it was difficult to identify morphology alone in other morphological types proposed by Di Biase, they had multiple internal lobulations in common. Therefore, based on the studies with magnetic resonance imaging, considering the TEE imaging limitations, we propose the classification in nonthrombogenic, similar to the chicken wing morphology (smooth internal surface with just a large angle, similar to a chicken wing) and thrombogenic (irregular internal surface with several lobulations, characteristics that are present and common to the windsock, cactus and cauliflower types). In the analysis of these 2 groups classified as thrombogenic and non-thrombogenic, a higher incidence of the non-thrombogenic type was found, as in the study published by Di Biase et al., ${ }^{3}$. No correlation was found with echocardiographic data of presence of thrombus or spontaneous contrast, but there was an association with clinical history of stroke/TIA (25.2\% in the thrombogenic group $\times 11.2 \%$ in the nonthrombogenic group, $\mathrm{p}=0.005)$. Besides, it was clear that individuals with a $\mathrm{CHA}_{2} \mathrm{DS}_{2} \mathrm{VASc}$ score between 0 and 1 , almost half had a thrombogenic morphological aspect. This finding underscores the importance of evaluating the thrombogenic risk profile and discussing early anticoagulation in this population (see table 3 ).

We believe that these additional data may contribute to the evaluation and conduct of patients who are candidates to anticoagulant therapy, especially in those with $\mathrm{CHA}_{2} \mathrm{DS}_{2}-\mathrm{Vasc}=1$, when doubts as to treatment persist.

\section{Limitations}

The data analyzed in this study were taken from different echocardiographic device models (GEVingmed Ultrasound, Vivid 7 and S6, Horten, Norway and ESAOTE My Lab 70, Florence, Italy), but there is no warning on any international guideline on the variation in the reference values of the parameters acquired in our analysis, considering different pieces of equipment. ${ }^{17,18}$

Unfortunately, the patients in our study did not perform any nuclear magnetic resonance imaging or computed tomography for comparison purposes. Therefore, based on the models proposed by these methods, we suggest a classification using TEE: nonthrombogenic (similar to chicken wing, as it has a smooth internal surface with prominent angulation) and thrombogenic (irregular internal surface with no well-defined angulation, as seen in cauliflower, cactus and wind sock shapes). Given our results consistent with MRI, we believe that TEE helps characterizing LAAs with a higher risk of stroke/TIA, but comparative studies are required to confirm our hypothesis.

\section{Conclusions}

There is an association between the morphodynamic abnormalities evaluated using TEE and $\mathrm{CHA}_{2} \mathrm{DS}_{2}-$ VASc score. The higher the $\mathrm{CHA}_{2} \mathrm{DS}_{2}$-VASc score, the more frequent are the abnormal echocardiographic findings, especially in patients with AF. There was a higher occurrence of stroke/TIA in patients with LAA morphology considered thrombogenic by TEE, even in those with sinus rhythm.

\section{Author contributions}

Conception and design of the research: Linhares RR, Moreira DAR. Acquisition of data: Linhares RR, Peixoto LB, Cruz AP, Garcia LP. Analysis and interpretation of the data: Linhares RR, Moreira DAR, Peixoto LB, Cruz AP, Garcia LP. Statistical analysis: Linhares RR, Peixoto LB, Cruz AP, Garcia LP. Writing of the manuscript: Linhares RR, Moreira DAR, Barretto RBM, Le Bihan DCS, Silva CES. Critical revision of the manuscript for intellectual content: Linhares RR, Moreira DAR, Barretto RBM, Le Bihan DCS, Silva CES. 


\section{Potential Conflict of Interest}

No potential conflict of interest relevant to this article was reported.

\section{Sources of Funding}

There were no external funding sources for this study.

\section{Study Association}

This study is not associated with any thesis or dissertation work.

\section{References}

1. Wann LS, Curtis AB, January CT, Ellenbogen KA, Lowe JE, Estes NA,et al; ACCF / AHA Task Force Members. 2011 ACCF / AHA/HRS focused update on the management of patients with atrial fibrillation (Updating the 2006 Guideline): a report of the American College of Cardiology Foundation/American Heart Association Task Force on Practice Guidelines. Circulation. 2011;123(1):104-23.

2. Kirchhof P, Benussi S, Kotecha D, Ahlsson A, Atar D, Casadei B, et al; 2016 ESC Guidelines for the management of atrial fibrillation developed in collaboration with EACTS. Eur Heart J. 2016;37(38)2893-962.

3. Di Biase L, Santangeli P, Anselmino M, Mohanty P, Salvetti I, Gili S, et al . Does the left atrial appendage morphology correlate with the risk of stroke in patients with atrial fibrillation? Results from a multicenter study. J Am Coll Cardiol. 2012; 60(6):531-8.

4. Leung DY, Black IW, Cranney GB, Hopkins AP, Walsh WF. Prognostic implications of left atrial spontaneous echo contrast in nonvalvular atrial fibrillation. J Am Coll Cardiol. 1994;24(3):755-62.

5. Wang Y, Di Biase L, Horton RP, Nguyen T, Morhanty P, Natale A. Left atrial appendage studied by computed tomography to help planning for appendage closure device placement. J Cardiovasc Electrophysiol. 2010;21(9):973-82.

6. Moore KL, Persaud TVN. The Developing Human. Clinically Oriented Embryology. 6th edition. Philadelphia, PA: WB Saunders Company, 1998.

7. Lip GY, Nieuwlaat R, Pisters R, Lane DA, Crijns HJ. Refining clinica risk stratification for predicting stroke and thromboembolism in atrial fibrillation using a novel risk factor-based approach: the euro heart survey on atrial fibrillation. Chest. 2010;137(2):263-72.

8. Chao TF, Lin YJ, Tsao HM, Tsai CF, Lin WS, Chang SL, et al. CHADS(2) and CHA(2)DS(2)-VASc scores in the prediction of clinical outcomes in patients with atrial fibrillation after catheter ablation. J Am Coll Cardiol. 2011;58(23):2380-5.

9. Lip G. What is the most effective and safest delivery of thromboprophylaxis in atrial fibrillation?. J R Coll Physicians Edinb. 2012;42(Suppl 18):35-44.

10. Bayard YL, Omran H, Neuzil P, Thuesen L, Pichler M, Rowland E, et al. PLAATO (Percutaneous Left Atrial Appendage Transcatheter Occlusion) for prevention of cardioembolic stroke in non-anticoagulation eligible

\section{Ethics approval and consent to participate}

This study was approved by the Ethics Committee of the Instituto Dante Pazzanese de Cardiologia, São Paulo - Brasil, under the protocol number 875.528. All the procedures in this study were in accordance with the 1975 Helsinki Declaration, updated in 2013. Informed consent was obtained from all participants included in the study.

atrial fibrillation patients: results from the European PLAATO study. EuroIntervention. 2010;6(2):220-6.

11. Dawson AG, Asopa S, Dunning J. Should patients undergoing cardiac surgery with atrial fibrillation have left atrial appendage exclusion? Interact Cardiovasc Thorac Surg. 2010;10(2):306-11.

12. Lip GY, Lin HJ, Chien KL, Hsu HC, Su TC, Chen MF, et al. Comparative assessment of published atrial fibrillation stroke risk stratification schemes for predicting stroke, in a non-atrial fibrillation population: The Chin-Shan community cohort study. Int J Cardiol. 2013;168(1):414-9.

13. Poçi D, Hartford M, Karlsson T, Herlitz J, Edvardsson N, Caldahl K. Role of the CHADS2 score in acute coronary syndromes - risk of subsequent death or stroke in patients with and without atrial fibrillation. CHEST. 2012;141(6):1431-40.

14. Providência R, Botelho A, Trigo J, Quintal N, Nascimento J, Mota P, et al. Possible refinement of clinical thromboembolism assessment in patients with atrial fibrillation using echocardiographic parameters. Europace. 2012;14(1):36-45.

15. Willens HJ, Gómez-Marín O, Nelson K, D Nicco A, Moscucci M. Correlation of CHADS2 and CHA2DS2-VASc scores with transesophageal echocardiography risk factors for thromboembolism in a multiethnic United States population with nonvalvular atrial fibrillation. Am Soc Echocardiogr. 2013;26(2):175-84.

16. Parikh MG, Aziz Z, Krishnan K, Madias C, Trohman RG. Usefulness of transesophageal echocardiography to confirm clinical utility of CHA2DS2-VASc and CHADS2 scores in atrial flutter. J Cardiol. 2012;109(4):550-5

17. Lang RM, Badano LP, Mor-Avi V, Afilalo J, Armstrong A, Ernande $\mathrm{L}$, et al. Recommendations for cardiac chamber quantification by echocardiography in adults: An update from the American Society of Echocardiography and the European Association of cardiovascular imaging. J Am Soc Echocardiogr. 2015;28(1):1-39.e14.

18. Hahn RT, Abraham T, Adams MS, Bruce CJ, Glas KE, Lang RM, et al. guidelines for performing a comprehensive transesophageal echocardiographic examination: Recommendations from the American Society of Echocardiography and the Society of Cardiovascular Anesthesiologists. J Am Soc Echocardiogr. 2013;26(9):921-64. 